\title{
TERRITÓRIO, IDENTIDADE E POLÍTICA NO PLANEJAMENTO URBANO- METROPOLITANO \\ Os Lugares de Urbanidade Metropolitana no contexto da Região Metropolitana de Belo Horizonte- Brasil
}

\author{
María Florencia Sosa \\ Mestranda NPGAU-UFMG \\ Orientadora: Dra. Jupira Gomes de Mendonça \\ arq.florenciasosa@gmail.com
}

\section{RESUMO}

Este trabalho discute os efeitos da implantação dos "Lugares de Urbanidade Metropolitana - LUMEs", um programa de políticas públicas proposto no Plano Diretor de Desenvolvimento Integrado da Região Metropolitana de Belo Horizonte. Três experiências pilotos dos LUMEs foram analisadas como casos de estudo. A importância do programa radica em que visa promover e qualificar a ação cidadã no processo de planejamento. Explora-se a hipótese de que estes espaços contribuem na formação da identidade metropolitana, colaborando para uma estrutura de governança mais cooperativa. Os resultados indicam que os LUMEs apresentam-se como potenciailizador da formação de identidades locais; entretanto, constituemse primeiramente como espaços que promovem uma participação social mais engajada quando ligados às tomadas de decisão vinculadas aos lugares do cotidiano. Apresentam-se limitações com relação ao interesse em ir além das demandas iniciais e ao envolvimento com outros processos que levem à politização e aproximação com o sistema político-administrativo.

Palavras Chave: Identidade metropolitana. Planejamento metropolitano. Governança metropolitana.

\begin{abstract}
This paper discusses the effects of the implementation of the "Places of Metropolitan Urbanity -LUMEs", a public policy program proposed in the "Integrated Development Plan for the Belo Horizonte Metropolitan Region". Three pilot experiences of LUMEs were analyzed as case studies. The importance of the program is that it aims to promote and qualify citizen action in the planning process. The hypothesis explored is that these spaces contribute to the formation of the metropolitan identity, collaborating for a more cooperative governance structure. The results indicate that the LUMEs are the driving force of the formation of local identities; however, they are primarily spaces that promote a more engaged social participation when linked in decision-making related to to everyday life spaces. Limitations are presented in relation to interests that go beyond the initial demands and to involvement whit other processes that lead to the politicization and approximation with the political-administrative system.
\end{abstract}

Key words: Metropolitan identity. Metropolitan planning. Metropolitan governance. 


\section{INTRODUÇÃO}

Nos últimos anos, na América Latina, começa a ser questionada a hegemonia do modelo de planejamento positivista tecnocrático, cartesiano e bidimensional, no qual se priorizavam alguns aspectos (econômicos acima de tudo). Evoluciona-se assim para um planejamento multidimensional e de múltipla escala, no qual se incluem novos enfoques como o ambiental, ou aspectos sociais e culturais e as estruturas políticas e institucionais continua a ser um tema complexo de se resolver.

A governança das regiões metropolitanas brasileiras continua marcada por estruturas institucionais fragmentadas e pela falta de coordenação entre agentes, gerando uma trajetória dos territórios metropolitanos que combina dinamismo econômico com profundas contradições socioespaciais e ambientais (MARICATO, 2011).

Desde o ano 2015 a Lei Federal denominada Estatuto da Metrópole, determina que devem se estabelecer diretrizes gerais para o planejamento, a gestão e a execução das funções públicas de interesse comum em regiões metropolitanas do Brasil e que devem funcionar como normas gerais sobre o plano de desenvolvimento urbano integrado e outros instrumentos de governança interfederativa no campo do desenvolvimento urbano.

No contexto da Região Metropolitana de Belo Horizonte (RMBH), caracterizada por grandes disparidades intra-metropolitanas, tem se adotado uma abordagem integral, multidimensional e de múltipla escala na elaboração do seu Plano Diretor de Desenvolvimento Integrado (PDDI-RMBH), contemplando espaços de mobilização social e política e incorporando outras relações, para além das funcionais e econômicas, que referem a sua frágil identidade metropolitana.

É de interesse mostrar que, mesmo adotando-se uma abordagem integral, multidimensional e de múltipla escala, a questão metropolitana continua a ser complexa, e que as regiões metropolitanas, além de ser o espaço adequado para a competitividade econômica, também podem ser concebidas como espaços de mobilização social e política (TOMÀS, 2015), e que uma participação cidadã legítima nas políticas metropolitanas pode ser dada através de uma abordagem do planejamento focado na construção de uma identidade metropolitana.

Este trabalho apresenta sucintamente os conceitos abordados na dissertação de mestrado, assim como apresenta os principais resultados.

A hipótese central é a de que um programa de política pública como o "Lugares de Urbanidade Metropolitana (LUMES)" pode contribuir no processo de formação e reforço da identidade metropolitana. A construção social de tal "identidade de projeto" (CASTELLS, 2001) metropolitana pode ser gerada a partir do fortalecimento de identidades locais que se interconectam em rede, o que gera uma "consciência metropolitana" que favoreceria a estabelecer um modelo de governança mais cooperativo e a uma gestão mais democrática e que dê maior legitimidade à institucionalização da escala metropolitana.

O reforço dos coletivos sociais apoiados pelos LUMEs, programa que promove uma dimensão politica e simbólica na (re) configuração de uma identidade metropolitana para a RMBH, se traduz no desenvolvimento de experiências de planejamento abertas, mais participativas e transdisciplinares.

Trata-se de atribuir uma identidade social própria às regiões metropolitanas, a partir do planejamento, com a expectativa de que um senso de pertencimento e de confiança resulte numa gestão mais democrática e dê maior legitimidade à institucionalização da escala metropolitana.

É objetivo principal do trabalho discutir o programa LUMEs proposto pelo PDDI-RMBH como política urbana na dupla leitura escalar (local e metropolitana), avaliando seu potencial para criação ou consolidação de uma identidade metropolitana.

São objetivos secundários: (1) Identificar e caracterizar este programa nos territórios local e o metropolitano; (2) Refletir sobre os limites e possibilidades da interferência dos municípios nas politicas metropolitanas; (3) Avaliar o processo inicial de implementação do programa e as mudanças geradas na configuração urbana metropolitana. 
A pesquisa iniciou-se com a revisão bibliográfica da literatura utilizada para a conceitualização de alguns pressupostos teóricos, que foram os construtores da pesquisa, para contextualização do tema. Os resultados desta etapa se encontram presentes nos capítulos desta dissertação.

Como procedimento metodológico, foi desenvolvida análise qualitativa através de estudo de caso de três experiências que foram desenvolvidas no âmbito de uma disciplina ofertadas na Escola de Arquitetura da UFMG, cujo escopo se alinha com os propósitos do Programa LUMEs, a saber: (1) O LUME Parque Municipal Barrocão em Matozinhos, (2) o LUME Espaço Cultural Casulo em Ribeirão das Neves e (3) a Feira Saia da Linha em Vespasiano. A revisão bibliográfica propiciou a formulação conceitual e a revisão dos documentos que deram origem ao programa abordado. Foram coletados dados através de entrevistas semiestruturadas com abordagem analítica qualitativa e de questionários com questões fechadas que ofereceram alguns indicadores quantitativos.

\section{O TERRITÓRIO METROPOLITANO E O PLANEJAMENTO}

Os territórios têm ficado à mercê do acionamento dos mecanismos de mercado, resultando em segregação socioterritorial (marcada pela informalidade e ilegalidade), aprofundamento das desigualdades sociais, fragmentação do tecido social e exacerbação da violência, quadro que se vê mais definidamente nas regiões metropolitanas brasileiras, onde "a acumulação da riqueza [...] caminha pari passu com a miséria" (CARLOS, 1992:32).

Ainda que os planos urbanos se constituam como um instrumento que pode prever e projetar a transformação desejada para o território, em prol de uma cidade que prime pela inclusão social e econômica e a justiça social e ambiental (UFMG, 2012), os planos também delimitam o território, o que pode implicar uma visão fragmentada (qual relação fica fora do plano, neste contexto de rede/região?), e propõem uma distribuição formal das competências para exercer e administrar o poder sobre o mesmo.

Território e escalas, identidade e cidadania, práxis política, região metropolitana, governança metropolitana e disparidades intrametropolitanas, são todos conceitos que, segundo nosso entender, podem nos aproximar do entendimento de uma nova forma de desenvolver o território, diferente do que propõe o modelo capitalista. Neste "novo modelo", ainda em gestação, prevalecem novas formas de interação social e, em consequência, de produção do espaço.

Saquet (2013) afirma que, junto às redes e à identidade, o poder é um dos componentes indispensáveis do território: as relações de poder são um componente fundamental na efetivação de um território e, mais ainda, "o campo da relação é um campo de poder que organiza os elementos e as configurações" (RAFFESTIN, 1993).

As grandes metrópoles do Brasil, dentre elas a RMBH, viram-se envolvidas no processo de globalização, processo este que "é objeto de leituras radicalmente contrastadas: desde uma forma de ocultação e de homogeneização das diferenças, das descontinuidades e das divisões do caráter econômico, cultural ou político, deixando pouco ou nenhum espaço para o desenvolvimento e a preservação da identidade local e chegando, inclusive, a regular a vida cotidiana dos indivíduos, até uma força que incrementa, por reação, a diferenciação entre os lugares." (NOGUÉ; RUFí, 2001:14, tradução nossa).

Giussepe Cocco (2007) expõe que, além de efeitos espaciais, as transformações contemporâneas do capitalismo envolvem a redução das funções e intervenções reguladoras do Estado e o enfraquecimento ou a desconstrução de articulações virtuosas entre o mercado, a democracia e a cidadania social que marcaram a sociedade salarial e o fordismo. Tais transformações têm levado a uma desregulamentação, flexibilização e fragmentação do mercado de trabalho, com a descoletivização, reindividualização e precarização dos contratos, dentre outras mudanças que têm enfraquecido identidades e solidariedades tradicionais e homogêneas de classe (COCCO, 2007).

Agora as formas de participação não são mais somente em instâncias tradicionais como os partidos ou agremiações. A sociedade política passa a fazer necessária a construção de novos espaços que fortaleçam os movimentos sociais e a formulação de projetos alternativos como reação da cidadania ao embate do capitalismo, ou tal como expõem Ciccolella e Mignaqui (2008), o empoderamento da sociedade civil e o surgimento de novas organizações sociais e formas inovadoras de acionar como outra característica desta etapa do capitalismo global. 
Mas, afinal, de que cidadania estamos a falar? A multiterritorialidade, que tem presença nas regiões metropolitanas, dificulta a formação de uma cidadania que se identifique com essa escala e que, consequentemente, participe dos mecanismos de governança metropolitana.

Castells (2001) propõe uma distinção entre três formas e origens de construção de identidades:

- "Identidade legitimadora: introduzida pelas instituições dominantes da sociedade no intuito de expandir e racionalizar sua dominação em relação aos atores sociais. [...]

- Identidade de resistência: criada por atores que se encontram em posições/condições desvalorizadas e/ou estigmatizadas pela lógica da dominação, construindo, assim, trincheiras de resistência e sobrevivência com base em princípios diferentes dos que permeiam as instituições da sociedade. [...]

- Identidade de projeto: quando os atores sociais, utilizando-se de qualquer tipo de material cultural ao seu alcance, constroem uma nova identidade capaz de redefinir sua posição na sociedade e, ao fazê-lo, de buscar a transformação de toda a estrutura social. [...]" (CASTELLS, 2001:24, grifo do autor)

\section{A GOVERNANÇA METROPOLITANA}

$\mathrm{Na}$ literatura internacional tem havido um amplo debate sobre a apropriação do termo governance, governability ou apenas government. Já na literatura brasileira, embora frequentemente não seja definido, encontra-se o termo governança. A autora arrisca aqui uma definição do que entende por isso a partir de elaborações de outros autores.

A governança é entendida como uma forma de governo sobre um território ou região, na qual todos os atores políticos (Estado, setor privado, sociedade civil, cidadãos, grupos, etc.) articulam seus interesses públicos e cooperam na negociação da formulação e implementação de políticas públicas. Uma governança democrática de uma RM deveria ter o objetivo de desenvolvimento equitativo, em que a efetiva colaboração de todos os atores visem uma RM mais cooperativa.

Para Putman (1996) uma sociedade civil forte e engajada é garantia de uma boa governança e a capacidade de seus cidadãos de cooperarem é proporcional à sua participação cívica, que pode considerar-se uma das formas do capital social.

Uma das maiores discussões sobre os arranjos metropolitanos surge do fato que a Constituição de 1988 considerou um modelo de três níveis, o Federal - a União-, o Estadual e o Municipal, mas não considerou uma quarta forma de organização territorial: as regiões metropolitanas. Isso porque se priorizou o papel dos municípios, que tinha sido minimizado durante o período militar (AZEVEDO; GUIA, 2015).

A RMBH possui uma composição de municípios muito heterogênea em termos econômicos e demográficos. Há grandes diferenças quanto às suas qualidades intraurbanas e, consequentemente, quanto à qualidade de vida de seus habitantes: cidades como Ribeirão das Neves ou Raposos são cidades-dormitório caraterizadas pela precariedade, ao passo que Nova Lima concentra os investimentos imobiliários de luxo. Em suma, a $\mathrm{RMBH}$ é assimétrica tanto em capacidade institucional quanto em recursos econômicos e políticos dentre os municípios que a constituem.

Sintetizando, o modelo centro-periferia da RMBH, assim como o de outras RM do Brasil, é desigual, hierárquico, excludente e segregador.

Segundo Tavares e Fonseca (2014) quando há uma sobreposição de escalas geográficas, há também uma sobreposição de escalas de poder, situação que requer criação de mecanismos de gestão compartilhada que, por um lado, não afetem a autonomia local e, por outro, não permitam um vazio institucional na escala metropolitana.

\subsection{Governança metropolitana na RMBH}

O caso da governança metropolitana na região em estudo apresenta grandes potencialidades, tendo em vista o novo arranjo institucional para a RMBH, em vigor desde 2006 : Assembleia Metropolitana, Conselho Deliberativo e Agência de Desenvolvimento Metropolitano, estabelecendo como instrumentos do 
planejamento metropolitano o Plano Diretor de Desenvolvimento Integrado (PDDI-RMBH) e o Fundo de Desenvolvimento Metropolitano.

Segundo Azevedo e Guia (2015), sob a perspectiva institucional, os mecanismos de gestão dificultam o processamento dos inúmeros problemas comuns aos municípios que conformam uma região metropolitana, problemas que requerem uma ação compartilhada.

O objetivo geral do programa LUMEs é contribuir para o incremento do sistema de planejamento metropolitano na $\mathrm{RMBH}$, através de ações de democratização da informação, de fortalecimento institucional, de ampliação da participação cidadã na gestão do território e de consolidação das ações de pesquisa dentro da UFMG, e um de seus objetivos específicos é conduzir a um maior dialogo nos territórios, junto às entidades da sociedade civil e poderes públicos (UFMG, 2011). Os ideadores do programa acreditam que atores cidadãos metropolitanos, construindo uma verdadeira identidade metropolitana podem exercer certa pressão social, que pode levar a uma mudança da cultura de "não cooperar" dos administradores dos municípios para outra que apresente maior abertura a novos arranjos de cooperação com estruturas de governanças menos fragilizadas.

\subsubsection{Percurso do planejamento e configuração institucional metropolitana na RMBH}

O processo de metropolização em Belo Horizonte se inicia nos anos de 1950, com um forte movimento migratório rural-urbano causado pelo processo de industrialização, o que leva a um processo de aglomeração populacional para além dos limites da capital (PLAMBEL, 1986).

A Constituição de 1967 determinou a realização de políticas de desenvolvimento e gestão intermunicipal, permitindo à União a criação de regiões metropolitanas, que deviam ser constituídas por Municípios que integrassem a mesma comunidade socioeconômica, visando à realização de serviços de interesse comum.

No ano 1973 o Governo Federal, naquela época sob comando dos militares, promulgou a Lei Complementar Federal $n^{\circ} 14$, que determinava, junto a outras sete ${ }^{1}$, a criação da RMBH com 14 municípios. Já que 0 processo de metropolização precisava de instrumentos de gestão que dessem conta dessa nova escala territorial e socioeconômica, no ano 1974 se criam, por meio da Lei Estadual 6303, duas instâncias de poder da Região Metropolitana de Belo Horizonte: os Conselhos Deliberativos e Consultivos da RMBH e o órgão técnico metropolitano, o PLAMBEL, cujo grupo executivo esteve encarregado da elaboração do primeiro Plano Metropolitano de Belo Horizonte. No ano seguinte, o Conselho Deliberativo aprova o Plano de Desenvolvimento Integrados Econômico e Social - PDIES, que se constituiu como um documento compreensivo que direcionava as ações no território da RMBH (PLAMBEL, 1986)

Já na década de 1980, a sociedade civil, descontente com o regime militar, exigia maior participação nos espaços políticos, "o que favoreceu a recuperação do espaço dos municípios [...] e a consequente substituição do modelo uniforme e centralizado de gestão metropolitana por um modelo mais representativo dos interesses municipais." (SOUZA, 2006). No ano 1996, depois de um período de esvaziamento e fragilização, o PLAMBEL é extinto.

A Constituição Federal de 1988 transfere para os Estados a prerrogativa de definir a gestão metropolitana. A Constituição do Estado de Minas Gerais, de 1989, estabelece um novo arranjo para a RMBH: a gestão metropolitana deveria ficar a cargo de uma Assembleia Metropolitana- Ambel, que estaria integrada por representantes de todos os municípios metropolitanos (para cada município o prefeito e um número de vereadores definidos por uma proporção da população municipal) e pelo estado, com um representante do Poder Executivo e um do Poder Legislativo. Tinha uma função normativa, regulamentar, administrativa, fiscalizadora, e deliberativa.

No ano 2004 se estabelece, através da Emenda Constitucional $n^{\circ}$ 65, um novo modelo institucional, vigente até hoje, para a gestão e o planejamento das regiões metropolitanas do Estado de Minas Gerais, do qual participam a Assembleia Metropolitana, a Agência de Desenvolvimento Metropolitano (ARMBH) e o Conselho Deliberativo de Desenvolvimento Metropolitano, no qual se dá lugar à participação da Sociedade Civil com dois representantes. Esse novo arranjo será explicado a seguir. 


\subsubsection{Os instrumentos do planejamento metropolitano para uma boa governança}

O PDDI-RMBH é um dos dois instrumentos de planejamento da ARMBH cujos objetivos são, por um lado, apresentar uma proposta de ordenação socioespacial do território da $\mathrm{RMBH}$, e por outro, apresentar um referencial institucional para o planejamento metropolitano, integrado e participativo para os 34 municípios da RMBH nas próximas décadas (UFMG, 2011). Foi elaborado entre os anos de 2009 e 2010 por uma equipe transdisciplinar na qual participaram a Universidade Federal de Minas Gerais (UFMG), a Pontifícia Universidade Católica (PUC Minas), a Universidade do Estado de Minas Gerais (UEMG) e representantes da sociedade civil e das administrações públicas municipais e estadual. Trata-se de uma experiência pioneira que busca promover a articulação dos vários interesses manifestos em prol do bem comum (MONTE-MÓR, 2012).

O Macrozoneamento Metropolitano é um documento previsto no PDDI-RMBH, no âmbito da Política Metropolitana Integrada de Regulação do Uso e da Ocupação do Solo, que norteia a gestão do uso e ocupação do solo em nível supramunicipal e por meio do qual se propõe a territorialização das políticas e programas indicados no PDDI-RMBH. Em relação às escalas, o Macrozoneamento é multi-escalar na sua dimensão social, pois abrange desde aspectos de incumbência metropolitana e regional até aqueles de escala local e da vida cotidiana (UFMG, 2014). Atualmente ainda não é Lei, mas o projeto está sendo discutido na Assembleia Legislativa de Minas Gerais. A sua aprovação deverá ser iminente para responder ao estabelecido pelo Estatuto da Metrópole.

As Conferencias Metropolitanas da RMBH são outro instrumento que incentivam à participação cidadã. Durante as Conferências, promovidas pela ARMBH, são escolhidos os representantes dos municípios e da sociedade civil no Conselho Deliberativo assim como também se forma o grupo que constituirá o Colegiado Metropolitano, todos para mandato de dois anos. Nestas Conferências também se discutem as questões que envolvem problemas do cotidiano nas cidades que constituem a RMBH, incluindo as funções públicas de interesse comum (FPIC).

\section{OS LUGARES DE URBANIDADE METROPOLITANA}

A proposta dos LUMEs (Lugares de Urbanidade Metropolitana) aparece no PDDI-RMBH como um programa de mobilização social para implementação do Plano Metropolitano, no âmbito da Política Metropolitana Integrada de Democratização dos Espaços Públicos. Os LUMEs têm o objetivo de dar seguimento ao processo participativo iniciado durante a elaboração do Plano, propondo promover a interatividade entre os diferentes âmbitos do arranjo institucional e instâncias politico-governamentais juntamente à sociedade organizada e aos cidadãos metropolitanos (UFMG, 2012).

Segundo estabelecido nos documentos do PDDI (2012) e no Macrozoneamento (2014), o objetivo geral do programa é organizar e difundir o conhecimento produzido na própria implementação do PDDI, os projetos em andamento e as prioridades em discussão, para assim garantir a participação e integração dos vários agentes metropolitanos no sistema de planejamento. Os objetivos específicos consistem em (1) promover a difusão do Plano em linguagem acessível ao grande público; (2) Fomentar a formação da cidadania metropolitana; (3) Articular a rede social existente na $\mathrm{RMBH}$ para acompanhamento do Plano e aprofundamento do processo participativo; (4) fomentar a construção da autonomia e da emancipação social dos grupos locais; (5) estabelecer relação com atividades de extensão universitária e ações de diferentes atores coletivos e institucionais (UFMG, 2014).

Compreende-se que não existe um modelo para os LUMEs e que cada um dos processos que emerge depende do contexto e das características da comunidade no qual se insere. Neste trabalho, pretende-se aborda-los como um estudo de caso que propõe uma visão "de baixo para cima" (bottom-up) do planejamento e como a concretização do discurso de aprendizado mútuo, ao ter a capacidade de incorporar o conhecimento local na construção de políticas metropolitanas.

Reconhece-se que a comunidade é quem tem a maior aptidão para identificar quais são os conflitos que a afeta, avaliar os impactos produzidos e gerar estratégias para sua mitigação, para que depois se construam, de forma conjunta, políticas públicas operacionalizadas pelo poder público que respondam a essas questões levantadas pela população. 


\subsection{Os LUMEs e o viés sociocultural do planejamento metropolitano}

Machado (2010) indica que um dos motivos dos altos custos de transação para os estados assumirem a gestão metropolitana é que há uma baixa ressonância da questão metropolitana nos movimentos sociais urbanos. A proposta dos LUMEs tem o potencial de reverter isto, a partir do propósito de gerar uma consciência em torno da importância das questões metropolitanas.

A necessidade de uma mobilização social permanente é manifestada expressamente no PDDI, pois um maior envolvimento dos cidadãos metropolitanos abonaria uma efetiva implementação do Plano. Ou seja, apela-se à implicação da comunidade como ator social que pode pressionar para que as diretrizes propostas sejam cumpridas.

O principal objetivo deste programa é construir um processo de colaboração e integração de conhecimentos entre os diversos atores metropolitanos que permita um constante exercício de crítica, análise e monitoramento do território e espaço da RMBH e, dentre os seus objetivos específicos, destaca-se que é o único programa que se propõe fomentar a formação da cidadania metropolitana (motivo fundamental para ter sido escolhido como estudo de caso para esta dissertação). Também são objetivos dos LUMEs contribuir para o crescimento do planejamento metropolitano, promover e qualificar cidadãos na gestão territorial, democratizar a informação, consolidar o senso de solidariedade, fortificar a governança urbana, expandir a pesquisa universitária e as atividades de extensão ao território (LIBÂNIO, 2016).

\subsection{Os LUMEs como produtores de capital social}

Como visto, tanto a ARMBH como os municípios periféricos carecem de recursos econômicos para desenvolver os projetos propostos nos LUMEs. Dada essa impossibilidade, propõe-se a hipótese de que os LUMEs têm o potencial para desenvolver-se como política pública voltada para o crescimento do capital social. O enriquecimento desse capital permitiria às comunidades (e aos municípios onde residem) uma vantagem no posicionamento dentro do modelo de governança vigente, além de estimular a ampliação da participação cidadã em assuntos políticos e, consequentemente, a construção da cidadania.

O capital social se refere à capacidade associativa da sociedade de trabalhar junto por objetivos comuns ou em mútuo beneficio, e é importante, sobretudo, porque promove, além da cooperação, o reconhecimento das ações coletivas. A literatura produzida sobre esse tema propõe que há uma relação entre capital social e o bom desempenho institucional. Estabelecida essa relação, se criaria um círculo virtuoso que fomentaria a confiança dos cidadãos nas instituições públicas e incentivaria a solidariedade e cooperação e, assim, quanto mais elevado o nível de confiança numa comunidade, maior a probabilidade de haver cooperação.

Durante as entrevistas com os mediadores observou-se que, quando estes davam sua própria definição dos LUMEs, traziam à tona, embora incipientemente, a importância do desenvolvimento dessas vantagens do capital social (cooperação, responsabilidade social, convívio, comunicação e consciência cívica, etc.).

"Os LUMEs são zonas de interesse metropolitano, onde a população interage, criando seu próprio espaço de lazer, interagindo com a sociedade. Os ZEIS (sic) [refere-se aos LUMEs] saem pouco do Poder Publico, e passa a responsabilidade para que a população assuma." (Mediador de Matozinhos, em entrevista concedida à autora em 06/09/2017, grifo meu)

"É lindo falar do LUMEs, porque o LUME é lugar de urbanidade metropolitana. No teatro que foi apresentado para a gente dentro do Macrozoneamento era tão bonito, era tão instigante, que gente, isso aí deve ser muito bom. E era a minha praia, porque tudo o que eu gostava de fazer estava ai, em relação à cultura, a arte e tudo. E quando nós fizemos o projeto e que resultou na feira, aí nós estamos vivendo o LUMEs assim, cotidianamente."(Mediador de Vespasiano, em entrevista concedida à autora em 09/06/2017, grifo meu)

"O termo é Lugares de Urbanidade Metropolitana. Eu acho que eu poderia definir como um lugar de referencia, um espaço de referencia para a sociedade, para a cidade se encontrar, discutir questões relacionadas à cidade, relacionada ao dia a dia, à questão do urbanismo, à cultura, a uma serie de coisas. Eu entendo o LUMEs como uma proposta 
de criação desse ambiente, de reflexão sobre a cidade." (Mediador de Ribeirão das Neves, em entrevista concedida à autora em 02/08/2017, grifo meu)

\subsubsection{Urbanidade e cidadania metropolitana}

Urbanidade, na sua definição de dicionário, é um substantivo que significa "qualidade do que é urbano". Os Lugares da Urbanidade vêm a propiciar tudo o que simboliza o urbano quanto às suas características sociais: as trocas e intercâmbios, a diversidade, o encontro, as intensas inter-relações. Por isso mesmo, segundo o PDDI, "todo o esforço de se pensar a urbanidade na RMBH está pautado nos termos de uma construção coletiva, multifacetada e que se quer a todo tempo solidária" (UFMG, 2012:750).

Em entrevista com um dos idealizadores do Programa LUMEs, surge também a questão de que desde sua concepção procurou-se incorporar a dimensão do empoderamento e do construir-se como cidadão, e que em seu entendimento essa perspectiva outorgada pela urbanidade bem poderia ser dada pelo conceito de cidadania.

Um dos objetivos específicos estabelecidos no Macrozoneamento para o Programa LUMEs era fomentar a formação da cidadania metropolitana. Tal como aparece no PDDI, se descreve a sociedade civil como historicamente excluída dos processos e tomadas de decisão do planejamento e gestão urbanos, e é por isto que se procura dar a ela um papel central como ator metropolitano (UFMG, 2014).

Uma das definições mais claras de cidadania foi dada por Marshall (1977), dizendo que "é um status concedido àqueles que são membros integrais de uma comunidade. Todos aqueles que possuem o status são iguais com respeito aos direitos e obrigações pertinentes ao status" (MARSHALL, 1977:76), ou seja, ser cidadão significa que um conjunto de direitos e obrigações dão igualdade a cada um dos habitantes do território.

No caso específico brasileiro, Santos (2014) refere-se a uma série de causas que contribuíram para a formação de não-cidadãos sob a forma de consumidores-usuários:

"a desruralização, as migrações brutais desenraizadoras, a urbanização galopante e concentradora, a expansão do consumo de massa, o crescimento econômico delirante, a concentração da mídia escrita, falada e televisionada, a degradação das escolas, a instalação de um regime repressivo com a supressão dos direitos elementares dos indivíduos, a substituição rápida e brutal, o triunfo, ainda que superficial, de uma filosofia de vida que privilegia os meios materiais e se despreocupa com os aspectos finalistas de existência e entroniza o egoísmo como lei superior, porque é o instrumento da buscada ascensão social. Em lugar do cidadão formou-se um consumidor, que aceita ser chamado de usuário." (Santos, 2014:25)

Ou seja, foram vários os processos, muitos relacionados diretamente com o neoliberalismo, que determinaram que toda capacidade de construir a cidadania seja ofuscada pela alienação da população, como consumidores. Bauman (2007: 290) afirma que "a concepção do cidadão como consumidor satisfeito é o grande problema".

Nesse aspecto, podemos afirmar que nem todos habitantes da RMBH são cidadãos, pois não apenas por ser portador desse "rótulo-status" de cidadão se é cidadão. A cidadania deve tornar-se, primeiro, consciência. Segundo Sandia e Rojas (2012)

La ciudadanía existe, está en todos nosotros, es inherente y se vuelve realidad material en la acción social, cuando comprendemos que somos comunidad con intereses, deseos y esperanzas, con palabras y mitos que nos constituyen como humanidad.

La ciudadanía es humanidad, es espacio de significaciones pero también de realizaciones, de luchas y derrotas, de derechos y compromisos, y todo ello en un marco de sentido consciente y transformador, liberador, inclusivo y democrático. (SANDIA E ROJAS, 2012:201)

O assunto da cidadania metropolitana foi colocado em questão no documento do PDDI, que o coloca não mais como objeto do planejamento, mas como sujeito do planejamento. Trata-se de fomentar a consciência 
dele como sujeito político através do sentido de identidade e do fortalecimento do exercício da cidadania (UFMG, 2012).

Segundo Sandia e Rojas (2012), a cidadania pode ser entendida a partir de duas perspectivas:

Por una parte, del poder, como un conjunto que lucha por el reconocimiento y conquista de derechos en un espacio de conflicto en el que se busca hipotéticamente superar las desigualdades; y, por la otra, del poder y la ciudadanía, como el espacio "ideal" de libertad y ejercicio de derechos y deberes democráticos que trascienden los límites de una institucionalidad y una legislación estatal y nacional. Estas diferentes representaciones y significaciones de la ciudadanía convergen, sin embargo, como espacio en construcción de otra esfera social que interroga el declive y agotamiento del modelo tradicional. Este nuevo orden temporal y espacial de experiencias, expresa, de algún modo, la lucha por la conquista de espacios y poder político, así como aboga por una ampliación de derechos humanos y ciudadanos y una real participación democrática (SANDIA E ROJAS, 2012:194, grifo meu).

\subsubsection{Participação cidadã}

Depois do período do regime militar, a população pleiteou por uma maior participação no âmbito da política social, o que derivou na adoção de um modelo de gestão mais participativo, com mais possibilidades de acesso aos atores sociais (movimentos sociais, sociedade civil organizada, ONGs, etc.) no sentido de participar das novas esferas como os Conselhos de Política Urbana e programas de orçamento participativo. Entretanto, considera-se que existe um déficit de participação e de constituição de atores relevantes que deem presença na gestão pública.

Na literatura sobre o tema é recorrentes a menção de diversos fatores que desestimulam a participação social: relações de poder desiguais, limitações da expressão da participação, desmotivação para a participação, limitações dos espaços tradicionais de participação social.

A finalidade das propostas contidas no Programa de Mobilização Social para a Implementação do Plano Metropolitano do PDDI-RMBH é qualificar a participação cidadã no planejamento metropolitano fomentando, para isso, a formação da cidadania metropolitana como uma das ações propostas.

Para ampliar a participação democrática é importante que a população conheça e reconheça as estruturas que governam a região metropolitana, que saibam quem toma as decisões sobre sua gestão. Mas isto não garante uma mobilização da sociedade. Azevedo e Guia (2015), ao analisar os padrões de decisão e de interação política relativos às regiões metropolitanas brasileiras, destacam que

[...] mesmo supondo, hipoteticamente, que a curto prazo fosse possível para a maior parte da população compreender os objetivos e a importância da questão institucional das regiões metropolitanas, ainda assim esse fato não levaria necessariamente a uma reversão do quadro de uma baixa prioridade política, porque, entre outros aspectos, transformações institucionais não significam o usufruto de benefícios imediatos, mas apenas possibilidades de vantagens futuras. Mesmo supondo que o rumo das mudanças possa engendrar fortes reflexos positivos a médio e longo prazos, isso ocorrerá, via de regra, de forma paulatina, fragmentada e, portanto, pouco perceptível para a população que reside nas áreas metropolitanas, dificultando, até entre grupos potencialmente beneficiados por um melhor desempenho institucional, uma maior prioridade para o tema, vis-a-vis de outros issues urbanos que envolvam bens públicos ou coletivos (transporte, postos de saúde, escolas, delegacias de polícia, etc.) (AZEVEDO E GUIA, 2015:530)

Como explicado, partimos do preceito de que, ao fomentar a participação se estimula o senso de pertença e a identidade, e que isto propiciaria a criação de laços mais estreitos na comunidade, ou dito de melhor maneira, quando há vínculos comunitários os sujeitos se sentem parte e identificados com essa comunidade, o que os leva a participar das esferas decisórias sobre políticas que alteram seu território comunitário. 


\subsubsection{Identidade cidadã e identidade Metropolitana}

Como foi problematizado na hipótese, a identidade pode ser considerada um recurso político (Castells, 2001). Segundo Christian Lefèvre (2005) a identidade metropolitana é condição necessária para que as decisões de políticas públicas nessa escala sejam mais legítimas democraticamente, e tal legitimidade é o que permite governar uma metrópole.

Para vários autores a identidade é um componente primário do território, para outros é definida a partir de um território (Castells, 2001; Mendes, 2005; Saquet, 2013;). Em um ponto todos concordam. Ou seja que a produção de identidade está estreitamente relacionada à produção territorial, pois o território "permite dar um caráter concreto, espacial e por tanto, quase material à identidade" (LÉON, 2015, tradução nossa).

Castells (2001) postula que

[...] do ponto de vista sociológico, toda e qualquer identidade é construída. A principal questão, na verdade, diz respeito a como, a partir de quê, por quem, e para quê isso acontece. A construção da identidade vale-se da matéria-prima fornecida pela história, geografia, biologia, instituições produtivas e reprodutivas, pela memória coletiva e fantasias pessoais, pelos aparatos de poder e revelações de cunho religioso. Porém, todos esses materiais são processados pelos indivíduos, grupos sociais e sociedades, que reorganizam seu significado em função de tendências sociais e projetos culturais enraizados em sua estrutura social, bem como em sua visão de tempo/espaço. Avento aqui a hipótese de que, em linhas gerais, quem constrói a identidade coletiva, e para quê essa identidade é construída, são em grande parte os determinantes do conteúdo simbólico dessa identidade, bem como o seu significado para aqueles que com ela se identificam ou dela se excluem. Uma vez que a construção social da identidade sempre ocorre em um contexto marcado por relações de poder [...] (CASTELLS, 2001:23-24, grifo meu).

A importância de construir uma identificação territorial mais assertiva ou conveniente se deve, tal como explica Rofman, (2016), a que a relação de cidadania baseia-se primeiramente no fato de ser parte de um território, tanto no plano jurídico e de direito quanto no identitário. E assim, "a pertença a coletivos delimitados espacialmente é o que habilita a atores da sociedade a interagir com o Estado como cidadãos e a participar, como tais, na vida política e nos processos de política pública (ROFMAN, 2016:17, tradução nossa). Também para Pollice (2010) a identidade territorial é uma ferramenta no âmbito da arena política que colabora com uma governança mais cooperativa: aumenta o nível de convergência sobre as decisões e reduz os comportamentos oportunistas ou ideológicos. Portanto, ao discutir a identidade da cidadania, estamos discutindo sua qualidade política.

Segundo esse autor, a identidade é importante para guiar os processos metropolitanos, pois tem um caráter estruturante capaz de produzir sentido, de orientar o agir coletivo e os processos de territorialização (Pollice, 2010).

No diagnóstico realizado para a elaboração do PDDI (eixo Urbanidade), as identidades locais e a identidade metropolitana foram reconhecidas como potencialidades, visto que quando discutido esse assunto nos grupos de discussão, revelou-se que "essa questão, tão necessária para a atuação compartilhada na RMBH, tem mobilizado a atenção das pessoas" (UFMG, 2012:117).

Calhoun (1995, 1991a, apud MENDES, 2005) realiza uma categorização das identidades, e coloca a identidade do lugar como uma identidade social primária, pois parte das relações sociais diretas, de base territorial, enquanto define a identidade metropolitana como categorial, também de base territorial. As identidades categoriais são aquelas que "assentam nas relações sociais indiretas, não deixando comtudo ser reais, de ligarem os seus membros e de definirem os campos de poder em que são importantes para a definição de identidades." (MENDES, 2005: 512).

Dentre as formas de serem construídas as identidades locais e a identidade metropolitana o Macrozoneamento (UFMG, 2014) propõe:

- preservação do patrimônio histórico e cultural dos municípios e, por extensão, da RMBH; 
- atividades de inclusão produtiva, tais como empreendimentos solidários, economia criativa, turismo de base comunitária e agricultura urbana;

- criação de uma marca que dê distinção e conhecimento das áreas.

Para Pollice (2010), quando temos processos inovadores, como é a proposta do PDDI-RMBH e do Macrozoneamento para a RMBH, a identidade pode colaborar para o seu êxito, no desenvolvimento e implementação. Isto é, uma vez definidos os objetivos no processo político de elaboração do Plano, ainda deve-se encarar um processo de apropriação por parte das comunidades.

Também se vela pela identidade territorial no Macrozoneamento: "há a necessidade de se promover a criatividade, a diversidade cultural, o senso de identidade territorial, a tolerância étnica e social e a sustentabilidade ambiental, com o uso de energias alternativas, princípios básicos de uma "novíssima economia" (UFMG, 2014:118).

A identidade pode ser definida pela diferença ou, como Woodward (2007:9) melhor define, "sustentada pela exclusão". Este autor procura categorizá-la segundo dois grupos em oposição: nós e eles. Na RMBH, é esta a primeira identidade que emerge, aquela marcada pela diferença: a relação centro-periferia, onde Belo Horizonte é o centro e a periferia é "todo o demais", todo o que ela exclui. A periferia costuma ser vista como uma massa homogênea carente de identidade, quando na realidade é uma identidade metropolitana renegada.

Segundo Dematteis a periferia se define, em primeira instancia, como a parte que rodeia ao centro. Não obstante, a condição de "periféricos" dos municípios da RM vai além de sua condição topográfica, pois "a periferia" da RMBH não se refere exatamente como a aposição diametralmente oposta a Belo Horizonte, centro e cidade polo da RMBH, mas aos pobres.

Por outro lado, temos a identidade do lugar. Dentre os motivos da ausência dessa identidade nas regiões metropolitanas, temos por um lado, os processos próprios da metropolização: os processos migratórios, o rápido crescimento das cidades, a alienação das massas moradoras das periferias com nada de tempo depois do trabalho (gasto nos grandes deslocamentos) para observar e refletir sobre as identidades, as relações sociais e o interesse em estabelecer laços comunitários e a inserção das regiões metropolitanas no processo de globalização.

Nos casos abordados, para exemplificar, podemos afirmar que Ribeirão das Neves passou por todos esses processos da metropolizacão, resultando em uma imagem negativa e até derrotista. Já Matozinhos, município que teve um processo de metropolização diferente, mais suavizado, e que atualmente possui um nível médio de integração metropolitana, mais baixo em relação aos outros municípios em estudo, é visto como um Município emergente, o que outorga uma identidade com uma maior "autoestima".

Por ultimo, acredita-se que formação primeira de uma identidade cidadã vinculada ao lugar, seria, nas palavras de Castells (2001) "uma reação defensiva" ante esta identidade metropolitana atual, de exclusão e degradação. Fortalecer as identidades locais interconectadas em rede, tal a hipótese desta dissertação, permitiria a posteriori uma apropriação do território (política e socialmente) metropolitano de uma forma muito mais legítima pois, "quando o mundo se torna grande demais para ser controlado, os atores sociais passam a ter como objetivo fazê-lo retornar ao tamanho compatível com o que podem conceber" Castells (2001:85).

\section{CASOS LUMES: UMA TRAJETÓRIA EM CONSTRUÇÃO}

A falta de recursos e a não institucionalização do Macrozoneamento não permitiram a implantação do programa de política urbana em análise. Assim sendo, acadêmicos da UFMG se apropriaram dos princípios do Programa e desenvolveram uma proposta de ensino seguindo seus preceitos. Assim, a partir do primeiro período de 2016 é ofertada pela Escola de Arquitetura da Universidade Federal de Minas Gerais (UFMG) uma disciplina curricular de graduação intitulada "Oficina Multidisciplinar: Os LUMEs e a prática do planejamento metropolitano", na qual se desenvolveram algumas experiências.

Até o primeiro semestre do ano 2017, tinham sido desenvolvidas oito delas na RMBH, todas vinculadas a esta disciplina. Para o estudo de caso foram selecionados três: (1) O LUME Parque Municipal Barrocão em Matozinhos, (2) o LUME Espaço Cultural Casulo em Ribeirão das Neves e (3) a Feira Saia da Linha em Vespasiano. 


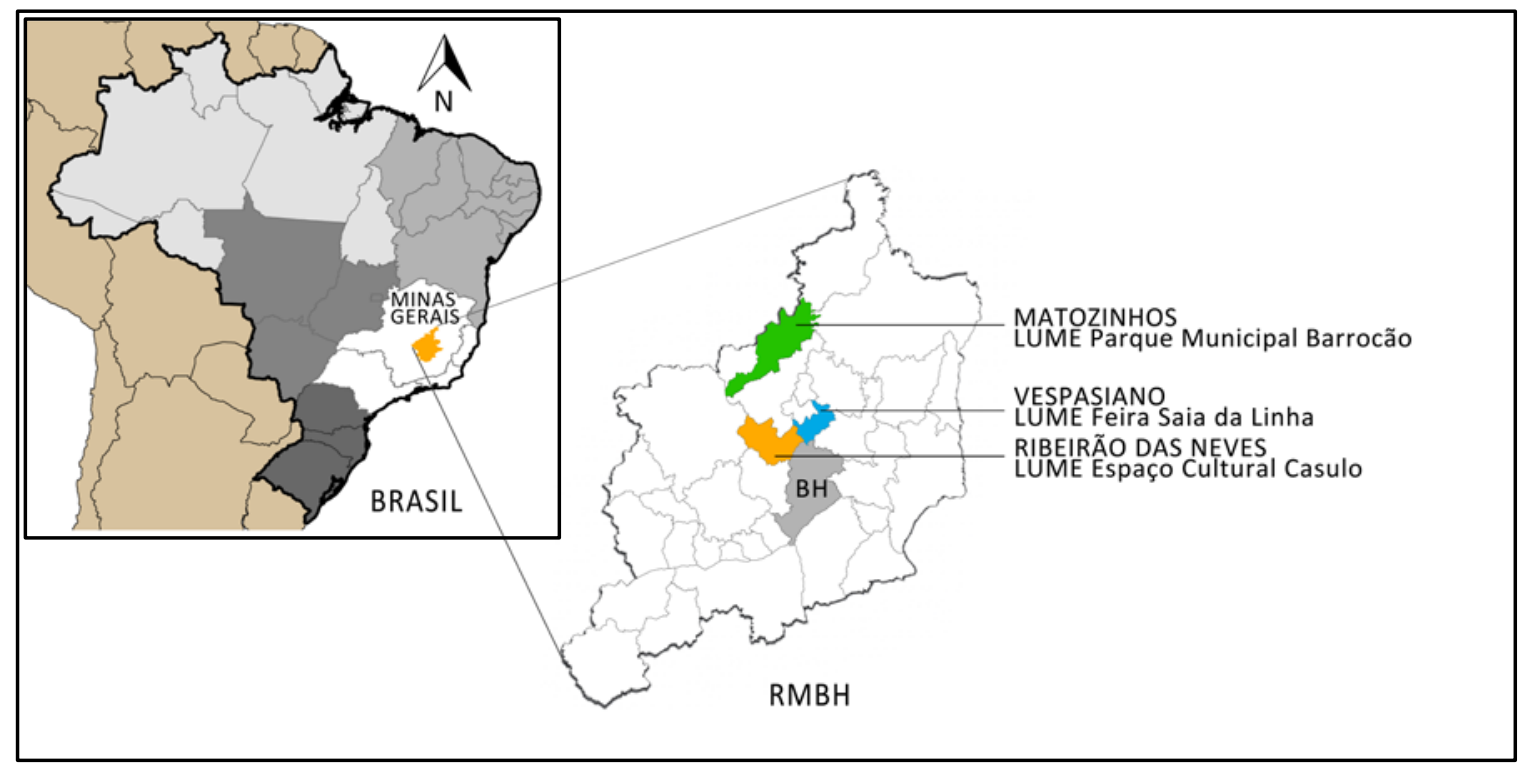

Localização dos municípios em estudo

Fonte: Elaboração própria

Não nos ocuparemos aqui em fazer uma avaliação do Programa segundo o delineamento do PDDI, mas é relevante para a hipótese aqui proposta destacar alguns dos aspectos que contribuiram para a reflexão sobre o papel dos programas de políticas públicas na formação das identidades territoriais (locais e metropolitanas) e para a ampliação de formas de participação social em questões relativas ao planejamento metropolitano.

O Quadro 1 sistematiza as principais informações sobre os projetos analisados neste trabalho e resume as principais informações coletadas em relação aos conceitos abordados: escala territorial, participação e configurações de identidades.

Embora cada um dos casos tenha tido suas especificidades, podemos acrescentar à sínteses que:

- Sobre o lugar

- No caso do LUME Casulo e do LUME Barrocão são resgatadas áreas de propriedade pública que estavam ociosas e não cumpriam função social alguma.

- O LUME Barrocão tem o potencial para ser um espaço de escala metropolitana, mas ainda é necessário ser mais reconhecido na escala local. Já o LUME Saia da Linha, que tem a expectativa de ser um lugar metropolitano, pode ter mais dificuldades em lográ-lo devido, principalmente, à sua localização.

- O Vetor Norte e a proximidade ao aeroporto internacional de Confins são elementos que, provavelmente pelo seu potencial de desenvolvimento econômico, interessam como recurso identitário a todos os municípios contemplados nesta pesquisa.

- Sobre a participação e a mobilização:

- Sobre as formas de organização, todos formaram em algum momento uma Comissão.

- Todos se apoiaram no uso do Facebook para a organização de reuniões eventos.

- As redes sociais e os panfletos foram os canais mais escolhidos para a divulgação de eventos e ações.

- São grupos formados por sectores populares da sociedade.

- O perfil do participante coincide com as características de um cidadão metropolitano: migrante e com alto grau de mobilidade pendular.

- Dão resposta às demandas populares.

- Não atuam de forma articulada com outros LUMEs. Ainda é exclusivamente a disciplina da UFMG o canal articulador entre eles.

- No caso do LUME Barrocão e do Saia da Linha estão a caminho de consolidar-se como espaços autogeridos e autônomos. 


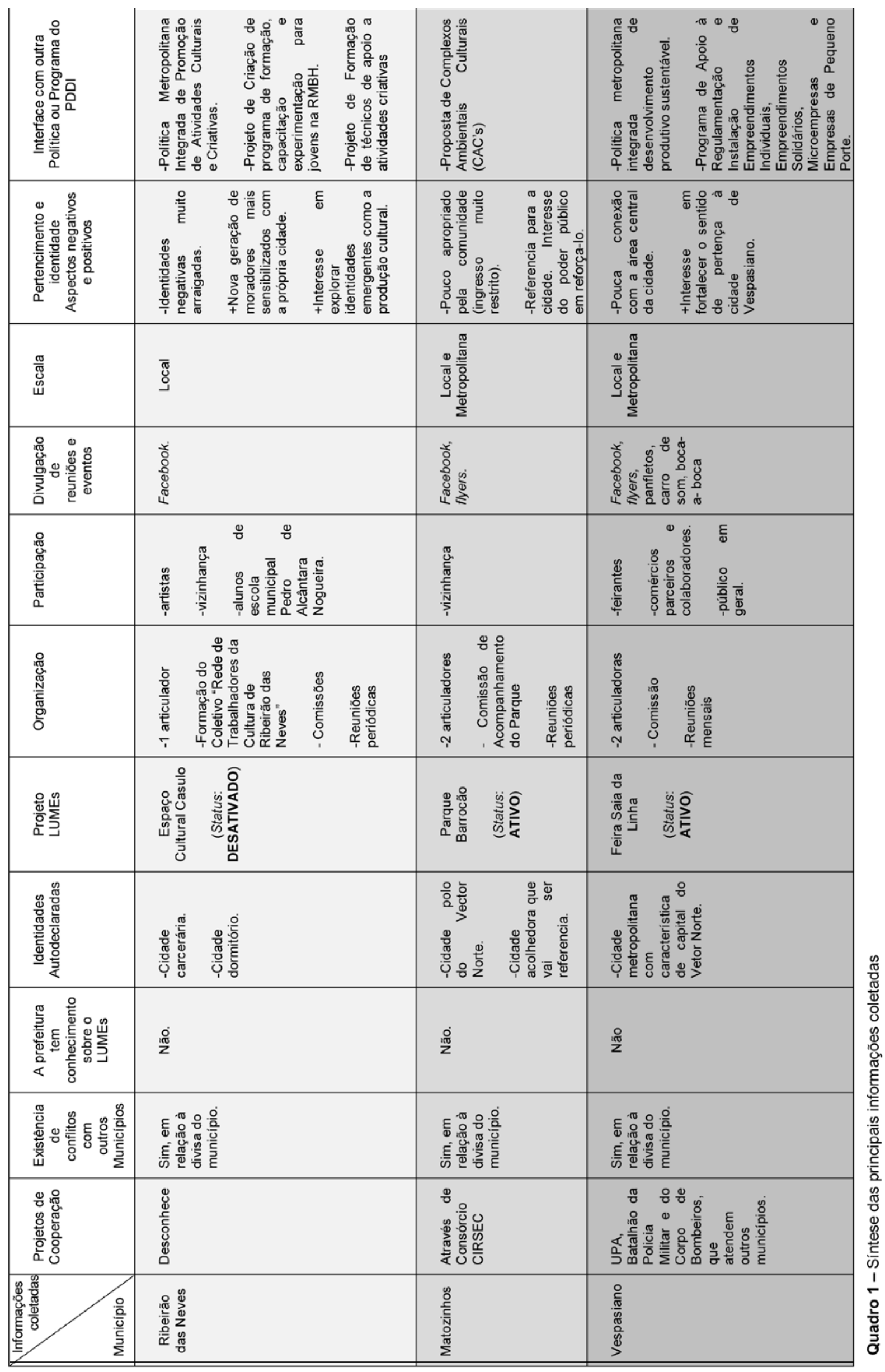




\section{Considerações finais}

A partir da análise do Programa LUMEs, da conjuntura que Ihe deu origem, e do contexto político-institucional no qual foi criado, se elaborou uma formulação teórica sobre os conceitos que o perpassam: lugar, cidadania e participação. Estes, nortearam a abordagem dos estudos de caso, três dos Projetos LUMEs desenvolvidos no marco da disciplina "Oficina Multidisciplinar: Os LUMEs e a prática do planejamento metropolitano", que tomou como referência metodológica o Programa LUMEs proposto no PDDI, foram estudados.

Os LUMEs oportunizam ações de cooperação e coordenação em espaços onde se tem acesso às informações. Efetivar-se-iam, assim, a formulação de políticas bottom-up, legitimadas por responderem às demandas dos cidadãos. Potencialmente, se as experiências (e atores) se articulassem em rede, descobrirse-iam problemas e ambiências comuns entre os grupos, que podem ser tratados ou cogeridos por mais de um grupo, ou ainda, se mobilizados, obteriam respostas das suas reinvindicações através dos órgãos metropolitanos.

Teórica e idealmente, podemos considerar o Programa LUMEs como uma política emancipatória, orientada à libertação, à justiça e à igualdade social. Talvez um programa desse escopo, que aspira a afrontar demasiados problemas, devesse recortar seus objetivos, priorizando alguns deles em um primeiro momento. Ainda, ao ser efetivado deveria aumentar-se a capacidade, ainda fraca, da população, de intervir desde a esfera social local na construção de políticas.

Dentre as fortalezas, destaca-se que este instrumento permitiu imaginar a construção de uma nova cidadania social para depois imaginar uma nova cidadania política, do exercício continuado de discussões cidadãs.

Sobre as experiências, deve ser destacado o papel dos mediadores, aqueles atores que introduziram no seu próprio território o Programa LUMEs e fizeram a articulação entre a escala local e a urbano-metropolitano, figuras chaves para iniciar o diálogo entre as necessidades e desejos das comunidades (nas quais se inserem e compreendem) e a administração superior. São por agora, os únicos pivôs entre a escala local e a metropolitana.

A partir do seguimento dos casos, observou-se que, fora de um reduzido círculo (que inclui mediadores e um reduzido número de participantes mais envolvidos), o alcance do objetivo de qualificar a participação contínua do cidadão no processo de planejamento dos espaços é ainda exíguo. As informações e discussões sobre a Região Metropolitana foram quase nulas. A preocupação com os assuntos metropolitanos não se constitui, ainda, em algo capaz de mobilizar as pessoas para atuar para além de sua zona de interesse.

Portanto, não podemos afirmar ainda que está se dando início a uma tradição associativa, pois a criação de redes é mínima, mas podemos ver que está começando a ser criado um tecido social "desde abaixo" que, com o decorrer do tempo, esperamos que se torne mais denso e resulte no aumento do capital social.

Para se tornar sujeitos do planejamento, os indivíduos precisam de espaços onde possam exercer essa participação ativa. A partir de quando se assumem como sujeito possuidor de poder como capacidade transformadora da realidade, esse comportamento desinteressado nos assuntos da política seria transformado. Começando a construir, na prática do cotidiano, não apenas uma identidade metropolitana, mas um incremento do interesse de tomar decisões referentes aos âmbitos da política como decisores de seu projeto de vida, formando e qualificando a população local como sujeitos capazes de inferir no planejamento dos espaços do seu cotidiano. Um próximo passo ou ajuste seria o de imaginar uma agenda de discussão desses temas, onde os cidadãos se concebam já por dentro das estruturas, dos espaços e do território.

Trabalho árduo será transmudar as identidades de estigma, pois como Bauman (1999) interpreta, esta é uma identidade difícil de ser negada, por mais que os estigmatizados tentm afirmar uma outra identidade. Constatou-se que é também um anseio da comunidade a criação de novas identidades, reelaborando as existentes a partir dos lugares. Essa outra identidade, ou a que se quer, a mesma identidade de periferia, mas esvaziada de seu caráter de precariedade e inferioridade, deve ser construída de forma tal que seja uma identidade positiva tanto fora como dentro da comunidade e que seja sustentada continuamente.

Como argumentado anteriormente, os LUMEs são os promotores, mas não os criadores de identidade; a partir da revalorização desses espaços periféricos se influencia o sentimento de pertença à comunidade, hoje sujeita à uma identidade excludente e que não agrada. Só se verificará esta condição quando a participação 
na criação e gestão destes lugares se intensificar, a identidade elaborada tenha um alto grau de aceitação e as camadas populares encontrem-se mobilizadas.

\section{REFERÊNCIAS}

AZEVEDO, S. Y GUIA, V. R. M (2015). Reforma do Estado e federalismo: os desafios da governança metropolitana. Em: RIBEIRO, Luiz César de Queiros (org.). O futuro das metrópoles: desigualdades e governabilidade (525-551) Rio de Janeiro: Revan. $2^{\mathrm{a}}$ ed.

BAUMAN, Z. (1999) Modernidade e ambivalência. Rio de Janeiro: Jorge Zahar.

- (2007) A Vida Fragmentada: ensaios sobre a moral pós-moderna. Tradução de Miguel Serras Pereira. Lisboa: Relógio d'Água.

CARLOS, A. F. A. (1992) A cidade. São Paulo: Contexto, Coleção repensando a geografia.

CASTELLS, M. (2001) A Era da Informação: Economia, Sociedade e Cultura; v. 2. O poder da Identidade. $3^{a}$ ed. São Paulo, Paz e Terra.

CICCOLELLA, P y MIGNAQUI, I. (2008) Metrópolis latinoamericanas: fragilidad del Estado, proyecto hegemónico y demandas ciudadanas: Algunas reflexiones a partir del caso de Buenos Aires. CDC, Caracas, v. 25, n. 69 (47-68) Disponível em < http://www.redalyc.org/articulo.oa?id=40311392004>. Acesso em 25/07/2016.

COCCO, G. (2007) M. Do quebra-cabeça do desenvolvimento à constituição do comum. Em: Sarah Feldman, Ana Fernandez. (Org.). O Urbano e o Regional no Brasil Contemporâneo (69-89) Salvador-São Paulo: Edufba - Editora Unesp - Anpur.

LEFÈVRE, C. (2005) Gobernabilidad democrática de las áreas metropolitanas. Experiencias y lecciones para las ciudades latinoamericanas. Em: Rojas, Cuadrado-Roura y Fernández-Güell (Eds.) Gobernar las metrópolis, BID.

LIBÂNIO, C. (2016) Reversal of priorities and possible confrontations: the role of the planning and the public policies in reduction of inequalities, in the expansion of social justice and in the realization of the right to the city in the metropolis. IV World Planning Schools Congress. Rio de Janeiro, Brasil.

MACHADO, G. (2010) Transações federativas e governança metropolitana: escolhas institucionais e a trajetória de dependência na experiência brasileira. Em: KLINK, J. (Org.) Governança das metrópoles: conceitos, experiências e perspectivas. São Paulo: Annablume.

MARICATO, E. (2011) Metrópoles desgovernadas. Estud. av., São Paulo , v. 25, n. 71 (7-22) Apr. 2011. Disponível em: <http://www.scielo.br/scielo.php?script=sci_arttext\&pid=S010340142011000100002\&lng=en\&nrm=iso >. Acesso em: 23/10/2017.

MARSHALL, T. (1977) Cidadania, classe social e status. Trad. Meton Porto Gadelha. Rio de Janeiro: Zahar.

MENDES, J. M. O. (2005) O desafio das identidades. Em: SOUSA SANTOS, Boaventura de (Org.). A globalização e as ciências sociais (503-540)3 ed. São Paulo: Cortez.

MONTE-MÓR, R. L. (2012) Planejamento Metropolitano em Belo Horizonte: uma experiência universitária. Em: RIBEIRO, Ana Clara, LIMONAD, Ester, GUSMÃO, Paulo Pereira (Orgs.) Desafios ao planejamento (95112) Rio de Janeiro: ANPUR. Letra Capital.

NOGUÉ, J. y RUFí J. (2001). Geopolítica, identidad y globalización. Barcelona, Ariel Geografía.

PLAMBEL (1986) A estrutura urbana da RMBH - V.1 - O processo de formação do espaço urbano 18971985. Belo Horizonte: PLAMBEL. 
POLLICE, F. (2010) O PAPEL DA IDENTIDADE TERRITORIAL NOS PROCESSOS DE DESENVOLVIMENTO LOCAL. Espaço e Cultura, [S.I.], n. 27 (7-24), jun. 2010. ISSN 2317-4161. Disponível em: http://www.e-publicacoes.uerj.br/index.php/espacoecultura/article/view/3539 . Acesso em: 04/03/2017. doi:https://doi.org/10.12957/espacoecultura.2010.3539.

PUTMAN, R. D. (1996) Comunidade e democracia. A experiência da Itália moderna. Rio de Fundação Getulio Vargas, 2006. $5^{\mathrm{a}}$ edição.

ROFMAN, A. ( 2016) Participación, políticas públicas y territorio: aportes para la construcción de una perspectiva integral . Rofman ... [et al.] ; compilado por Adriana Rofman. - 1a ed . - Los Polvorines : Universidad Nacional de General Sarmiento.

SANDIA, C. M. Y ROJAS P. H. (2012) La Ciudadanía como Co-construcción de Espacios de Participación en lo Público. Em: Sociologias (192-213) Porto Alegre, ano 14, n. 31, set./dez. 2012.

TOMÁS, M. (2015) If urban regions are the answer, what is the question? Thoughts on the European experience. Em: International Journal of Urban and Regional Research. V. 39. Número 2.

RAFFESTIN, C. (1993) Por uma Geografia do poder. São Paulo: Ática.

SANTOS, M. (2014) O Espaço do Cidadão. 7a Edição, 2a reimpressão. São Paulo. Nobel. $1^{\mathrm{a}}$ ed 1987

SAQUET, M. (2013) Abordagens e concepções de território. $3^{\circ}$ ed. São Paulo: Expressão popular.

SOUZA, T. R. (2006) Titularidade de gesto metropolitana: O caso de Belo Horizonte. Dissertação (Mestrado em Ciências Sociais) - Pontifícia Universidade Católica, Minas Gerais, Belo Horizonte.

TAVARES, S. R. Y FONSECA, M. L. P. (2014) Governança em regiões metropolitanas emergentes: relações intermunicipais. XIV Simpósio de Geografia da UDESC. $2^{\circ}$ Seminário Nacional De Planejamento e Desenvolvimento. Florianópolis.

UFMG (2011) Plano Diretor de Desenvolvimento Integrado da Região Metropolitana de Belo Horizonte $P D D I-R M B H$. Relatório Final: Produto 6 - Definição de propostas de políticas setoriais, projetos e investimentos prioritários (em seis volumes). Belo Horizonte, UFMG.

- (2014) Plano Metropolitano - Macrozoneamento RMBH. Produto 1: Marco teórico metodológico e definição das áreas temáticas afetas ao interesse metropolitano. Belo Horizonte.

WOODWARD, K. (2007) Identidade e diferença: uma introdução teórica e conceitual. In. SILVA, Tomaz Tadeu da (Org.). Identidade e diferença: a perspectiva dos estudos culturais (7-72) Petrópolis, RJ: Vozes

\section{Fuentes electrónicas:}

LÉON, S. (2015) L'identité, une ressource dans les stratégies métropolitaines? Métropolitiques, 8 juin 2015. Disponível em: http://www.metropolitiques.eu/L-identite-une-ressource-dans-les.html. Acesso em: 02/10/2017. 